DOI 10.37882/2223-2982.2021.09-2.18

\title{
ФОРМАНТНАЯ СТРУКТУРА ГЛАСНЫХ КАК ПАРАМЕТР РЕАЛИЗАЦИИ РИТМИЧЕСКОЙ СТРУКТУРЫ СЛОВА В РЕЧИ НОСИТЕЛЕЙ РУССКОГО ЯЗЫКА В АЗЕРБАЙДЖАНОЯЗЫЧНОМ ОКРУЖЕНИИ
}

\section{THE FORMANT STRUCTURE OF VOWELS AS A PARAMETER FOR THE REALIZATION OF A RHYTHMIC WORD STRUCTURE IN THE SPEECH OF AZERBAIJAN-BASED RUSSIAN SPEAKERS}

V. Nekrylova

Summary: The current article presents the results of a phonetic experiment conducted in 2019-2020. The research is aimed to analyze the rhythmic structure of words in the interfering speech of Russian speakers who live in Azerbaijan. The localization of the formant regions of stressed vowels and unstressed syllables in the speech of Russian speakers in an Azerbaijani-speaking environment was considered. In the speech of members of the diaspora, in most cases, realizations are recorded with the placement of vowel formant regions that is normative for the modern Russian literary language (which is explained by the special form of coexistence of the Russian and Azerbaijani languages). At the same time, among the native speakers of the Russian language in the Azerbaijanispeaking environment, the potential area of movement of the formant regions of the vowels towards the lower rise and more of the front row (which is characteristic of the vowels of the Azerbaijani language) is determined. This localization indicates a possible area of deformation of the rhythmic structure of the Russian phonetic word due to the influence of the Russian-Azerbaijani interference. The current article presents the results of a phonetic experiment conducted in 2019-2020. The research is aimed to analyze the rhythmic structure of words in the interfering speech of Russian speakers who live in Azerbaijan. The localization of the formant regions of stressed vowels and unstressed syllables in the speech of Russian speakers in an Azerbaijani-speaking environment was considered. In the speech of members of the diaspora, in most cases, realizations are recorded with the placement of vowel formant regions that is normative for the modern Russian literary language (which is explained by the special form of coexistence of the Russian and Azerbaijani languages). At the same time, among the native speakers of the Russian language in the Azerbaijani-speaking environment, the potential area of movement of the formant regions of the vowels towards the lower rise and more of the front row (which is characteristic of the vowels of the Azerbaijani language) is determined. This localization indicates a possible area of deformation of the rhythmic structure of the Russian phonetic word due to the influence of the Russian-Azerbaijani interference.

Keywords: Russian language, Azerbaijani language, rhythmic structure of a word, interference, word stress, formant structure of vowels.
Некрылова Виктория Петровна

Соискатель, Московский государственный университет

им. М.В. Ломоносова

nekrylova@ya.ru

Аннотация: В статье представлены результаты фонетического эксперимента, проведенного в 2019-2020 гг. В рамках исследования анализировалась ритмическая структура слова в интерферированной речи носителей русского языка, проживающих в Азербайджане. Рассмотрена локализация формантных областей гласных ударных и безударных слогов в речи носителей русского языка в азербайджаноязычном окружении. В речи представителей диаспоры в большинстве случаев зафиксированы реализации с нормативным для современного русского литературного языка размещением формантных областей гласных (что объясняется особой формой сосуществования русского и азербайджанского языков). При этом у носителей русского языка в азербайджаноязычном окружении определена потенциальная область перемещения формантных областей гласных в сторону нижнего подъема и более переднего ряда (что характерно для гласных азербайджанского языка). Данная локализация указывает на возможную область деформации ритмической структуры русского фонетического слова по причине влияния русско-азербайджанской интерференции.

Ключевые слова: русский язык, азербайджанский язык, ритмическая структура слова, интерференция, словесное ударение, формантная структура гласных. 


\section{Введение}

$\mathrm{B}$ статье представлены результаты ряда экспериментов, проведенных в рамках исследовательской работы «Реализация ритмической структуры русского фонетического слова в речи носителей тюркских языков и русского языка в тюркскоязычном окружении». Одной из целей данной работы является описание признаков фонетической интерференции в области просодии в речи носителей русского языка, находящихся в азербайджаноязычном окружении. Выявление признаков интерференции проводилось при помощи анализа ритмической структуры слова (далее - РСС) - важнейшей типологической особенности русского языка (подробнее см. [8, с. 256-302]). Настоящее исследование посвящено анализу локализации формантных областей гласных ударных и безударных слогов в речи носителей русского языка в азербайджаноязычном окружении и сопоставлению с данными, полученными для группы носителей современного русского литературного языка (далее - СРлЯ).

В результате исторического взаимодействия русского языка с национальными языками народов Кавказа возникают региональные (национальные) варианты русского языка, используемые в том числе и русскоговорящим населением [4, с. 7]. На эти специфические особенности звуковой реализации влияет не только национальный язык (например, грузинский, азербайджанский и др.), но и русская речь инофонов [5, с. 3].

Русский язык диаспоры в Азербайджане представлен в особых условиях существования (вне метрополии в разноязычном социуме - в тюркскоязычном окружении) и, безусловно, подвержен интерференции вследствие влияния азербайджанского языка. Фонетика является одной из областей проявления интерференции в речи представителей русскоязычного сообщества - отмечаются особенности при реализации гласных, согласных, интонации, возникшие по причине влияния другого языка [7]. Изменения в механизме редукции гласных, вариативность постановки словесного ударения [7, с. 79, 82] указывают на то, что просодия (в том числе РСС) русского языка подвержена интерференции.

Население современного Азербайджана составляет 9,8 миллионов человек, из которых примерно 5 миллионов владеет русским языком [1]. С 1998 года русский язык в Азербайджане считается иностранным, в настоящее время не имеет официального статуса. Русская община Азербайджанской Республики (крупнейшая организация русскоязычной диаспоры) действует с 1993 года, в Азербайджане насчитывается около 400 школ, где более 100 тысяч учащихся (примерно 15\%) получают образование на русском языке (в т.н. «русском секторе») $[2,6]$.
Традиционно считается, что словесное ударение в азербайджанском языке (как и в турецком) является фиксированным и обычно падает на конечный слог многосложного слова [13, с. 160], при этом отдельно оговариваются случаи, когда ударение не является конечнослоговым, что зависит от характера присоединяемых аффиксов (например, в спрягаемых формах глагола, наречиях, деепричастиях). Некоторые служебные слова, а также аффиксы сказуемости, глагольного отрицания и некоторые другие являются безударными. В словах, заимствованных из русского языка, место ударения обычно остается неизменным, однако в ряде общеупотребительных заимствованных слов ударение перемещается на конечный слог (например, лампа́) [13, с. 162].

Корректнее будет сказать, что ударение в азербайджанском языке является подвижным, слабым (иногда сложно определить, есть ли в слове ударение, иногда оно реализовано только в одном слове во всей фразе, что является следствием сосуществования словесного ударения с сингармонизмом) [14], ударение носит «плавающий», непостоянный характер, так как может переходить с одного аффикса на другой, конечнослоговой. При этом подвижность словесного ударения тюркских языков отличается от подвижности ударения русского языка - она является односторонней (ударение передвигается на последний аффикс словоформы, который и образует слог) [3, с. 231].

Отметим, что, помимо представителей русскоязычной диаспоры Азербайджана (основным отличием которой от диаспоры в Турции [11, с. 103] является то, что это коренные жители, которые не эмигрировали, а родились и постоянно проживают в Азербайджане), в записи приняли участие естественные билингвы, усвоившие с рождения два языка (и русский, и азербайджанский, при этом в настоящий момент основным языком дикторы считают русский язык).

\section{Материалы и методы}

В рамках настоящего исследования применяется выработанная ранее экспериментальная база (дизайн эксперимента см. [11, с. 104-105]), были подготовлены материалы для чтения, состоящие из трех блоков: 1) 16 фонетических слов для изолированного произнесения, включающие трех- и четырехсложные лексемы СРЛЯ с различными РСС (например, под капо́том (РСC 4/3 - в четырехсложном слове ударение падает на третий слог), под ободо́к (РCC 4/4), господа́м (РCC 3/3), под то́nотом (РCC 4/2), хохото́к (РCC 3/3), доса́дам (РCC 3/2), па́тока (РСС 3/1) и др.); 2) 32 предложения, содержащие эти слова в сильной и слабой фразовых позициях (пример: Двигатель находится под капотом. Поскольку двигатель находится под капотом машины, к нему сложно подобраться); 3) связный текст, состоящий из 75 предло- 
жений и содержащий данные слова в сильной и слабой фразовых позициях (пример: Однажды утром Игнат не смог завести свой автомобиль. Явно что-то сломалось под капотом. Поэтому не получалось завести машину. А что именно заглохло под капотом машины, Игнат так и не смог разобраться).

Для анализа были использованы аудиозаписи 12 дикторов (10 женщин и 2 мужчин, от 18 до 66 лет на момент записи). 11 человек родились в Азербайджане, 1 человек - в России в азербайджаноязычной семье. Дикторы определяют в качестве родного/основного языка русский, постоянно находятся в азербайджаноязычном окружении (проживают в Азербайджане или в азербайджанской семье в России), часть дикторов ежедневно использует в повседневной коммуникации азербайджанский язык.

Для сопоставительного анализа были подготовлены аудиозаписи эталонных дикторов русского языка (5 дикторов, 2 мужчин и 3 женщины, возраст - от 25 до 59 лет, далее в тексте обозначены как дикторы-эталоны). Дополнительно использовались аудиозаписи дикторов, входящие в базу данных звучащей русской речи, разрабатываемую в лаборатории фонетики и речевой коммуникации филологического факультета МГУ имени М.В. Ломоносова. Для дикторов-эталонов было проанализировано 1597 реализаций гласных, для русскоязычных дикторов в Азербайджане - 3381 реализация.

Спектральные характеристики (F1 и F2) измерялись на стационарном центральном участке (в Гц) гласных ударного, 1-го и 2-го предударных, 1-го заударного слогов в изолированной, сильной и слабой фразовых позициях. В большинстве случаев значения формант вычислялись автоматически в программе Praat (версия 6.0.56) [15], но с визуальным контролем; иногда оказывалась возможной только ручная обработка. Учитывались все данные, нерелевантные реализации исключались. Для этого использовались функции «Get first formant» и «Get second formant» с настройками по умолчанию (метод Бурга, временное окно 25 мс, для женских голосов - частотный диапазон 5500 Гц для пяти формант, для мужских - диапазон 5000 Гц для пяти формант).

При анализе было необходимо по возможности снизить влияние физиологических и анатомических особенностей дикторов на имеющиеся данные, в связи с чем использовалась нормализация формантных значений по методу Б.М. Лобанова (о данном методе, этапах подготовки данных см. [16], [12, с. 58-60]), которая осуществлена с помощью интерфейса NORM v. 1.1, находящегося в открытом доступе в сети Интернет [18].

Используя нормализованные значения формант гласных ударного ([á], [ó]), 2-го и 1-го предударного, 1-го заударного слогов, возможно корректно оценить основную локализацию формантных областей и центроидов интерферированных гласных русского языка (в произнесении русскоязычных дикторов, находящихся в азербайджаноязычном окружении), оценить их расположение относительно формантных областей гласных в произнесении дикторов-эталонов.

На рисунках 1-3 представлены нормализованные значения формант гласных русских эталонов (круги) и представителей русскоязычной диаспоры в Азербайджане (квадраты) в сопоставлении (ось X - нормализованные частотные значения F2, ось Y - нормализованные частотные значения F1; эллипсами обозначено стандартное отклонение формантных значений гласного от его среднего значения).

Зависимость формантных значений от артикуляционных характеристик стандартная: чем выше значение частоты F1 (ось Y), тем ниже подъем гласного; чем выше значение частоты F2 (ось X), тем более передним является гласный. Условные обозначения для рисунков 1-3: RUSvAZ - группа носителей русского языка в азербайджаноязычном окружении, RUS_etalon - группа дикторов-эталонов, 1st pre - гласный 1-го предударного слога, 2nd pre - гласный 2-го предударного слога, 1st post - гласный 1-го заударного слога.

При формулировании гипотезы было очевидно, что при особых условиях сосуществования русского и азербайджанского языка нельзя ожидать заметных следов интерференции (как это было, например, при исследовании речи диаспоры в Турции [11]). При этом прогнозируется смещение формантных областей гласных (пусть и в незначительной степени), которое важно зафиксировать, так как оно указывает на те участки, которые подвержены интерференции в первую очередь.

Общая гипотеза для сопоставительного анализа заключается в ожидаемом нарушении механизмов качественной редукции в интерферированной русской речи представителей диаспоры, а именно - во влиянии формантных областей гласных азербайджанского языка на формантную структуру гласных русского языка, что вероятнее всего для гласных контрольных слов в слабой фразовой позиции (т.к. слово в данной позиции находится в зоне минимального внимания говорящего, что подтвердилось на предыдущих этапах исследования [11, с. 110]). При этом не ожидается подтверждения взаимосвязи фразовой позиции и формантной структуры гласных (что ранее было сформулировано для СРЛЯ, см. [9, с. 50]).

\section{Результаты исследования}

Проведено сравнение (1) нормализованных формантных областей гласных ударного ([á], [ó]), 2-го и 1-го 
предударного, 1-го заударного слогов при изолированном произнесении контрольных слов представителями русскоязычной диаспоры в Азербайджане и группы дикторов-эталонов (Рис. 1).

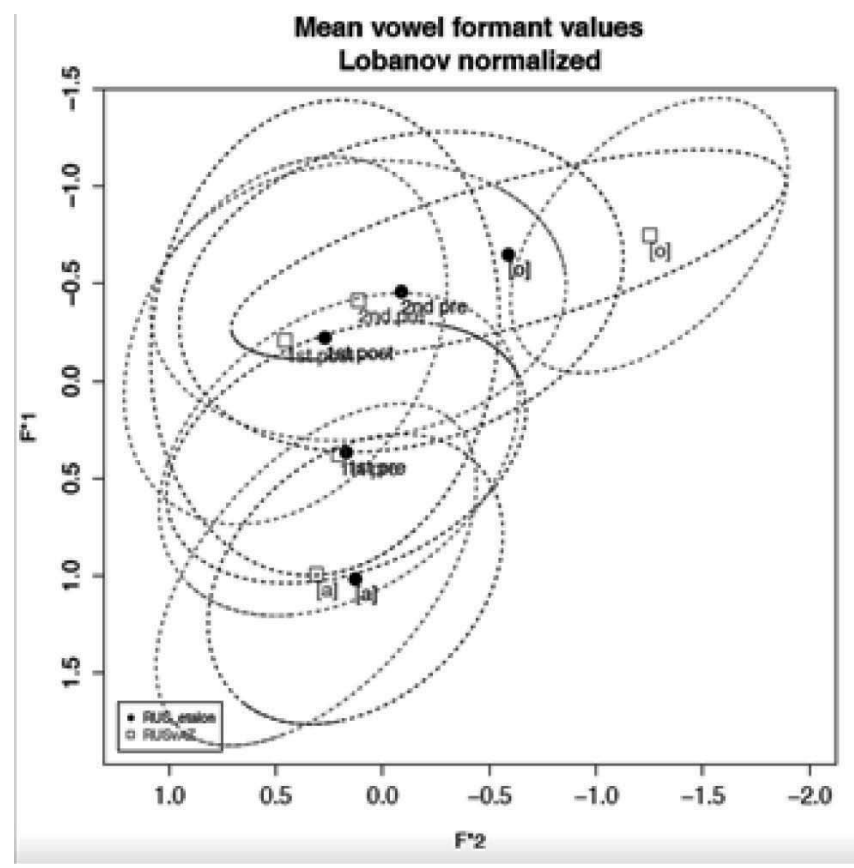

Рис. 1. Нормализованные гласные 2-го предударного, 1-го предударного, ударного и 1-го заударного слогов для представителей русскоязычной диаспоры в Азербайджане (квадраты) в сравнении с нормализованными гласными для русскоязычных дикторов-эталонов (круги) в контрольных словах в изолированном произнесении.

Гласный [ó] в контрольных словах в изолированном произнесении отличается произносительной стабильностью у группы русскоязычных дикторов в Азербайджане (о чем можно судить по площади эллипса). Расположение эллипса на графике указывает на то, что нормализованный [ó] в интерферированной речи имеет более нижний подъем (вероятно, по причине влияния азербайджанского языка, где $\mathrm{F} 1$ [о] $\approx 425-485$ Гц [17], в отличие от русского, где $\mathrm{F} 1$ [о] $\approx 400$ Гц [10, с. 82]). Гласный [á] по значениям F1 близок к реализации [á] дикторамиэталонами, у представителей диаспоры звук упереднен (возможно, в целом проявляется влияние упередненных гласных азербайджанского языка [5, с. 30] и/или отсутствие веляризации согласных в азербайджанском языке). Гласный 1-го предударного слога реализован нормативно, что указывает на сохранение механизмов оформления просодического ядра русского фонетического слова, несмотря на азербайджанско-русскую интерференцию и возможное влияние ритмической структуры слова в азербайджанском языке, в котором практически отсутствует количественная и качественная редукция гласных [3, с. 232]. Гласные 1-го заударного и 2-го предударного слогов находятся в одной зоне (т.н. зоне централизации), реализованы в целом нормативно, при этом наблюдается тенденция к более переднему ряду и нижнему подъему (что близко по значениям формант к азербайджанскому неогубленному гласному звуку заднего ряда верхнего подъема [w], сходному по звучанию с русским [ы]). На этапе аудитивного анализа записей представителей диаспоры также был отмечен частотный [ы]-образный призвук при реализации [ъ] в заударных слогах.

Проведено сравнение (2) нормализованных формантных областей гласных ударного ([á], [ó]), 2-го и 1-го предударного, 1-го заударного слогов в контрольных словах в сильной фразовой позиции для представителей русскоязычной диаспоры в Азербайджане и группы дикторов-эталонов (Рис. 2).

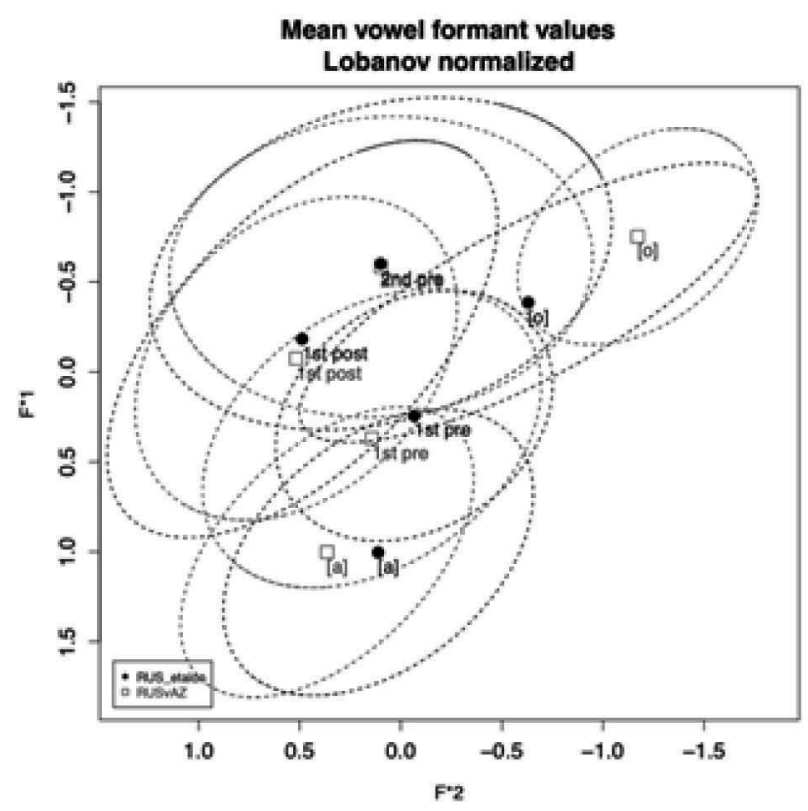

Рис. 2. Нормализованные гласные 2-го предударного, 1-го предударного, ударного и 1-го заударного слогов для представителей русскоязычной диаспоры в Азербайджане (квадраты) в сравнении с нормализованными гласными для русскоязычных дикторов-эталонов (круги) в контрольных словах в сильной фразовой позиции.

Соотношение формантных областей исследуемых гласных звуков аналогично соотношению данных параметров гласных в контрольных словах при изолированном произнесении (см. сравнение 1). Сохраняется тенденция перемещения формантных областей гласных в сторону более нижнего подъема и более переднего ряда (что, вероятно, объясняется локализацией формантных областей азербайджанских гласных [17]).

Проведено сравнение (3) нормализованных формантных областей гласных ударного ([á], [ó]), 2-го и 1-го 
предударного, 1-го заударного слогов в контрольных словах в слабой фразовой позиции для представителей русскоязычной диаспоры в Азербайджане и группы дикторов-эталонов (Рис. 3).

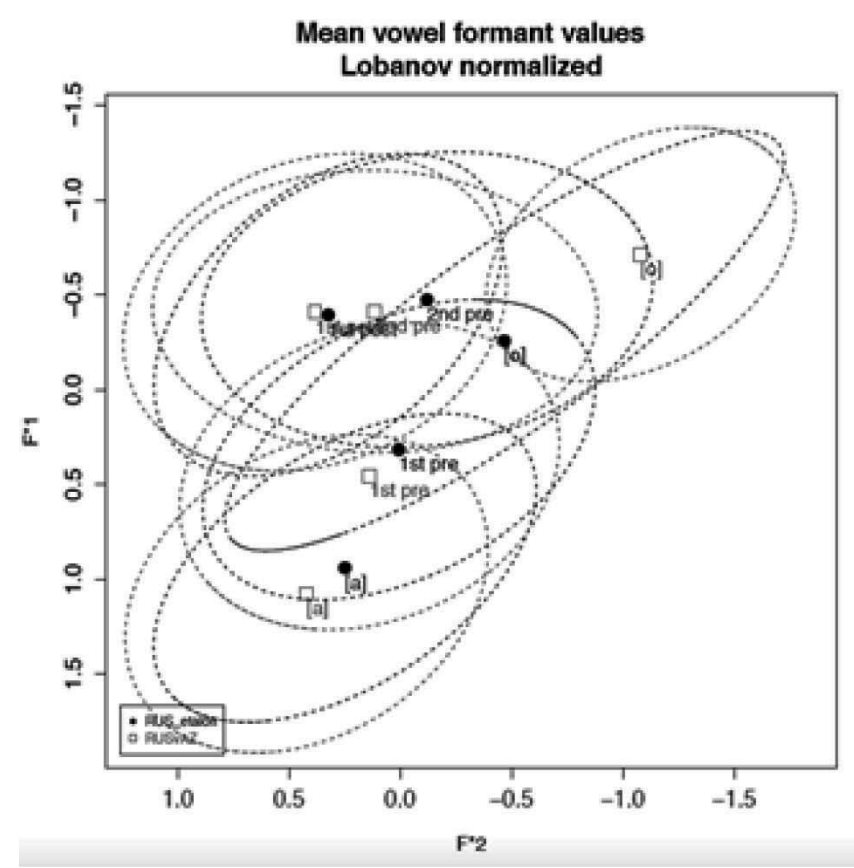

Рис. 3. Нормализованные гласные 2-го предударного, 1-го предударного, ударного и 1-го заударного слогов для представителей русскоязычной диаспоры в Азербайджане (квадраты) в сравнении с нормализованными гласными для русскоязычных дикторов-эталонов (круги) в контрольных словах в слабой фразовой позиции.

Соотношение формантных областей исследуемых гласных звуков аналогично соотношению данных параметров гласных в контрольных словах при изолированном произнесении и в сильной фразовой позиции (см. сравнение 1 и 2). Сохраняется тенденция перемещения формантных областей гласных в сторону более нижнего подъема и более переднего ряда. Так, в сильной и слабой фразовой позициях (для массива данных русскоязычных дикторов в Азербайджане) наблюдается перемещение формантной области гласного 1-го предударного слога (относительно центроида эллипса формантной области аналогичного гласного для дикторов-эталонов).

\section{Обсужмение}

В СРлЯ исследуемые гласные ударных и безударных слогов не отличаются друг от друга по формантному составу в зависимости от фразовой позиции [9, с. 50]. При этом и для дикторов-эталонов, и для представителей диаспоры у гласного 1-го предударного слога в слабой фразовой позиции наблюдается небольшая централизация формантных областей по сравнению с более сильными фразовыми позициями, что соответствует данным, полученным ранее для СРЛЯ [9, с. 50-51].

В русской речи представителей диаспоры сохраняется механизм оформления просодического ядра (в том числе на уровне формантной структуры), что еще раз доказывает его основополагающую функцию при формировании ритмической структуры русского слова. Вероятно, только в том случае, если будет зафиксировано разрушение просодического ядра, можно будет говорить о максимальной степени проявления интерференции (и глубокой деформации родного/основного языка диктора вследствие влияния второго/иностранного языка). При анализе зафиксировано перемещение формантных областей в зону переднего ряда и нижнего подъема гласных.

Наибольшее количество нормативных реализаций гласных просодического ядра отмечено при изолированном произнесении контрольных слов (при этом наблюдаются недостаточная редукция во 2-м предударном и 1-м заударном слогах, что, вероятно, объясняется интерференционным влиянием). В сильной и слабой фразовых позициях структура просодического ядра также сохраняется, при этом в слабой позиции наблюдается максимальное смещение формантной области 1-го предударного слога. Как и предполагалось, критических изменений формантной структуры гласных в речи представителей диаспоры зафиксировано не было (что объясняется также особой формой сосуществования русского и азербайджанского языков), при этом намечена потенциальная область перемещения формантных областей гласных у носителей русского языка в азербайджаноязычном окружении (упередненные гласные нижнего подъема).

\section{Зак^ючение}

Таким образом, несмотря на преобладание нормативной для СРЛЯ локализации формант гласных, можно наметить тенденцию к перемещению формантных областей вследствие межъязыковой интерференции. Нарушения механизма качественной редукции гласных не наблюдается, при этом происходят качественные изменения иного характера - перемещение центроидов (и, соответственно, эллипсов) гласных в сторону нижнего подъема и более переднего ряда (что характерно для гласных азербайджанского языка). Вариативность показателей F1 и F2 указывает на необходимость уточнения в дальнейшем схемы отбора материала (увеличения количества дикторов, статистического анализа данных для группы русскоязычных дикторов, постоянно использующих в повседневной жизни азербайджанский язык), применения дополнительных методов обработки полученных результатов. 


\section{Благодарности}

Автор выражает благодарность сотрудникам Бакин- ского славянского университета и Российского информационно-культурного центра в г. Баку за помощь в сборе экспериментального материала.

\section{ЛИТЕРАТУРА}

1. Агаева Ш.А. 0 речевых особенностях азербайджанского русского языка // Актуальные проблемы современной медицины и фармации 2019: сборник тезисов докладов LXXIII Международной научно-практической конференции студентов и молодых ученых, Минск, 15-17 апреля 2019 г. Минск, 2019. С. 1570.

2. Алхасов Я. Языковая политика в Азербайджане и содержание обучения русскому языку в азербайджанской школе // Русский язык за рубежом. 2007. № 6. С. 75-78.

3. Баданова Т.А. Словесное ударение в алтайском языке в сопоставительном аспекте. Новосибирск: Издательство НГУ, 2011. 316 с.

4. Байрамова Ф.О. Исследование акцента в интерферированной русской речи (на материале русской речи азербайджанцев): дис. ... канд. филол. наук. М., 2012. 297 C.

5. Бондарко Л.В., Вербицкая Л.А., Гордина М.В., Белякова Г.А., Игнаткина Л.В., Кукольщикова Л.Е., Литвачук Н.Ф., Огородникова К.С., Ошуйко Е.И., Сергеева Т.А., Штерн А.С., Щербакова Л.П., Щукин В.Г. Интерференция звуковых систем. Коллективная монография / Под ред. Л.В. Бондарко, Л.А. Вербицкой. Л.: Издательство ЛГУ, 1987. 278 с.

6. Гаджиев А. Образование на русском языке в Азербайджанской Республике: реалии и перспективы развития // Этнодиалоги. 2017. № 1 (52). С. $28-44$.

7. Земская Е.А., Гловинская М.Я., Бобрик М.А. Язык русского зарубежья: Общие процессы и речевые портреты / Под ред. Е.А. Земской. М.; Вена: Языки славянской культуры, 2001. 492 с.

8. Златоустова Л.В., Потапова Р.К., Потапов В.В., Трунин-Донской В.Н. Общая и прикладная фонетика. М.: Изд-во Моск. ун-та, 1997. 416 с.

9. КнязеВ С.В. Структура фонетического слова в русском языке: синхрония и диахрония. М.: МАКС-пресс, 2006.226 с.

10. Князев С.В., Пожарицкая С.К. Современный русский язык: фонетика. М.: Академический Проект, 2005. 320 с.

11. Некрылова В.П. Интенсивность гласных как параметр реализации ритмической структуры слова в речи носителей русского языка, проживающих в Турции // Вестник Московского университета. Серия 9: Филология. 2020. № 4. С. 102-113.

12. Черепанова 0.Д. Лингвистическое обеспечение фонетических тренажеров при обучении немецкому языку (на материале вокализма русского и немецкого языков): дис. ... канд. филол. наук. М., 2019. 185 с.

13. Языки мира. Тюркские языки: сборник статей / Гл. редкол.: В.Н. Ярцева. М.; Бишкек: Издательский Дом «Кыргызстан», 1997. 542 с.

14. Baitchura U. Instrumental-phonetik data on the word-stress and intonation in Azerbaijani. In: Central Asiatic Journal. Wiesbaden, Harrassowitz Verlag, 1979 , vol. 23, no. 1/2, p. 38-64.

15. Boersma, P., Weenink D. Praat: doing Phonetics by Computer. Version 6.0.56. 2020. URL: http://www.fon.hum.uva.nl/praat/ (дата 0бращения: 19.07.2021).

16. Lobanov B.M. Classification of Russian vowels spoken by different speakers. In: The Journal of the Acoustical Society of America, 1971, vol. 49, p. 606-608.

17. Mokari P.G., Werner S. An acoustic description of spectral and temporal characteristics of Azerbaijani vowels. In: Poznan Studies in Contemporary Linguistics, vol. 52, no. 3, 2016, p. 503-518.

18. Thomas, E.R., Kendall T. NORM: Vowel Normalization Suite 1.1 Methods. 2007. URL: http://www.lingtools.uoregon.edu (дата 0бращения: 20.07.2021).

(с) Некрылова Виктория Петровна (nekrylova@ya.ru). 